\title{
Evaluation of Carbon thin Films Using Raman Spectroscopy
}

\author{
Danilo Lopes Costa e Silva ${ }^{a *}$, Luciana Reyes Pires Kassab ${ }^{b}$, Antonio Domingues dos Santos ${ }^{a}$,
}

\author{
Marina Fuser Pillis ${ }^{c}$ \\ ${ }^{a}$ Instituto de Pesquisas Energéticas e Nucleares, Universidade de São Paulo, Av. Prof. Lineu Prestes, \\ 2242, Butantã, CEP 05508-000, São Paulo, SP, Brasil \\ ${ }^{b}$ Faculdade de Tecnologia de São Paulo, Praça Coronel Fernando Prestes, 30, Bom Retiro, CEP 01124- \\ 060, São Paulo, SP, Brasil \\ 'Instituto de Física, Universidade de São Paulo, Rua do Matão, 1371, CEP 05508-090, São Paulo, SP, Brasil
}

Received: September 01, 2017; Revised: March 15, 2018; Accepted: April 20, 2018

Carbon thin films deposited by the magnetron sputtering technique were evaluated by Raman spectroscopy to study the influence on their crystallinity caused by different parameters like the carbon deposition time, the different buffer-layers and substrates employed and also two distinct heat treatments. The present results showed that the choice of these parameters plays an important role in the production of these films. The results also indicate the possibility of using the technique for the production of carbon thin films to be employed in future in applications with controlled content of structural defects, predominance of ordered $\mathrm{sp}^{2}$ bondings and tendency of graphitization.

Keywords: carbon thin films, magnetron sputtering, nanographite.

\section{Introduction}

The vibrational spectroscopy has been contributing largely in many fields of materials science because of its versatility of non-destructive sampling methods ${ }^{1}$. Raman spectroscopy is a technique which has been broadly used to characterize diamond-like carbon (DLC) films, graphite and graphene films ${ }^{2-8}$. It has also been applied to detect stress in semiconductor films like $\mathrm{Si}$ and $\mathrm{SiC}$, in $\mathrm{ZrO}$ and $\mathrm{Cr}_{2} \mathrm{O}_{3}$ films which are oxidized at high temperatures and also carbon and bio tissue materials ${ }^{9}$. The literature has shown that the chemical flexibility of the carbon materials is grounded on the $\mathrm{sp}^{2}$ (graphite-like) to $\mathrm{sp}^{3}$ (diamond-like) bond ratio ${ }^{10}$. Generally, amorphous carbon films are composed of a mixture of $\mathrm{sp}^{3}, \mathrm{sp}^{2}$ and $\mathrm{sp}^{1}$ bondings with the existence of hydrogen and nitrogen that interconnect the chains ${ }^{10}$. Diamond films exhibit a single first-order band at $1332 \mathrm{~cm}^{-1}$ and large single-crystal graphite materials show a high frequency band at about $1550 \mathrm{~cm}^{-1}$. For other kinds of amorphous and nanocrystalline carbon films, the Raman spectrum typically shows a $\mathrm{G}$ peak centered around $1550 \mathrm{~cm}^{-1}$ and a $\mathrm{D}$ peak centered at $1360 \mathrm{~cm}^{-111}$. The $\mathrm{G}$ band is attributed to graphite-like structures of $\mathrm{sp}^{2}$ micro-domains and the $\mathrm{D}$ band is associated to the disorder activated breathing mode ( $\mathrm{A}_{1 \mathrm{~g}}$ symmetry) of the hexagonal rings of the graphitic structure, corresponding to $\mathrm{sp}^{2}$ bondings ${ }^{11}$. The $2 \mathrm{D}$ band $\left(2660 \mathrm{~cm}^{-1}-2710 \mathrm{~cm}^{-1}\right)$ is a double-resonance band. In monolayer graphene films its intensity reaches the maximum value (four times the value of the $\mathrm{G}$ band intensity) ${ }^{12}$. The structures of the $\mathrm{sp}^{2}$ bonded carbon atoms consist of various graphitic forms varying from nanocrystalline graphite to glassy carbon.
Safaie et al ${ }^{13,14}$ reported that the incorporation of oxygen in doped diamond-like carbon thin films results in changes of the optical and structural properties, and that by increasing the oxygen content in doped diamond like carbon films, the amount of $\operatorname{sp}^{2} \mathrm{C}=\mathrm{C}$ bonds was raised and the hydrogen content reduced in the structure. It was also shown that the oxygen concentration influences the $\mathrm{I}_{\mathrm{D}} / \mathrm{I}_{\mathrm{G}}$ ratio and its interference in the $\mathrm{sp}^{2}$ bonding fraction. Ferrari et al ${ }^{15,16}$ have proposed the amorphization trajectory to describe the increasing disorder of carbon structures, based on the variation of the $\mathrm{G}$ band position and of the $\mathrm{I}_{\mathrm{D}} / \mathrm{I}_{\mathrm{G}}$ intensity ratio.

In recent publications, our group has reported on the preparation of carbon thin films by magnetron sputtering ${ }^{17,18}$. This work presents new results of Raman Spectroscopy for carbon thin films produced by the magnetron sputtering technique, and also determines the influence of different parameters as deposition time, buffer-layer ( $\mathrm{Co}, \mathrm{Cu}$ and $\mathrm{Ni}$ ), substrate type and heat treatment on the crystallinity degree of the films. The use of metallic buffer layer is necessary to facilitate the formation of the crystalline structures. The lack of it would lead to completely amorphous thin carbon films that are not desired in the present study. As already shown in the literature ${ }^{19,20}$, the hexagonal symmetry of the Co (0002) buffer-layer and the small mismatch of the (111) $\mathrm{Cu}$ and $\mathrm{Ni}$ buffers in relation to the graphite lattice parameter, deposited on c-plane (0001) sapphire substrates or $\mathrm{Si}$ (111) substrates, are ideal templates for the growth of graphitic carbon films in CVD deposition processes. Therefore, these results, the few literature related to crystalline carbon thin films produced by the sputtering technique and our previous results motivated the present work, as most of the reported works on crystalline carbon films are normally based on the CVD technique ${ }^{20-24}$. 


\section{Materials and Methods}

The samples were produced by the DC magnetron sputtering technique using an ATC 2000 Sputtering System (Aja International Equipment), a 99.999\% pure Kurt J. Lesker graphite target and 99,95\% pure $\mathrm{Co}, \mathrm{Ni}$ and $\mathrm{Cu}$ Alfa Aesar targets. Different substrates were used for the deposition: c-plane (0001) sapphire, Si (100) and Si (111). Internal halogen lamp bulbs located behind the substrate holder allowed the deposition of the buffer-layers (BL) at a temperature range of $500^{\circ} \mathrm{C}-600^{\circ} \mathrm{C}$. The carbon (C) was deposited at room temperature. The base pressure was $10^{-7}$ Torr, the sputtering deposition pressure was 5 mTorr and a mixture of $95 \% \mathrm{Ar}$ and $5 \% \mathrm{H}_{2}$ was used as the plasma sputtering gas, aiming to avoid possible oxidation of the metallic BL's. The samples produced are described in Table 1.

Table 1. Samples produced using different substrates and buffer-layers.

\begin{tabular}{|c|c|c|c|c|c|}
\hline Buffer-layer & Cobalt & & Copper & & Nickel \\
\hline Substrates & $\begin{array}{c}\text { c-plane } \\
(0001) \\
\text { sapphire }\end{array}$ & $\begin{array}{c}\mathrm{Si} \\
(100)\end{array}$ & $\begin{array}{c}\mathrm{Si} \\
(111)\end{array}$ & $\begin{array}{c}\text { c-plane } \\
(0001) \\
\text { sapphire }\end{array}$ & $\begin{array}{c}\text { c-plane } \\
(0001) \\
\text { sapphire }\end{array}$ \\
\hline Samples & Co-1 & $\mathrm{Cu}-1$ & $\mathrm{Cu}-2$ & $\mathrm{Cu}-3$ & $\begin{array}{l}\mathrm{Ni}-1, \\
\mathrm{Ni}-2, \\
\mathrm{Ni}-3, \\
\mathrm{Ni}-4\end{array}$ \\
\hline
\end{tabular}

The heating of the substrates was performed only during the BL's depositions because a good crystallinity was necessary for the subsequent carbon film to be deposited. Otherwise, a considerable amount of carbon atoms would be expected to dissolve into the BL due to the higher carbon solubility. Also, during the substrate cooling down process, those atoms would return to the interface between the BL and the carbon film, compromising the surrounding crystal structure and the total thickness of the carbon films.
The samples with Ni buffer-layers were heat treated after the deposition of the carbon films according to two different procedures:

1. Sample Ni-1 was heat treated in a Lindberg Blue furnace Model STF55346C, under the pressure of 2.5 $\mathrm{x} 10^{-3}(\mathrm{~Pa})$, heating rate of $7^{\circ} \mathrm{C} / \mathrm{min}$, and maintained at $750^{\circ} \mathrm{C}$ for 12 minutes;

2. Sample Ni-2 was heat treated in a Lindberg MDL furnace Type: 59754 , in atmospheric pressure, heating rate of $375^{\circ} \mathrm{C} / \mathrm{min}$, maintained at $750^{\circ} \mathrm{C}$ for 12 minutes.

The Table 2 shows the deposition parameters: power, deposition temperature, deposition time, chamber pressure and the gas flux employed during each stage.

The Raman measurements were performed in a WITEC Confocal Raman Microscope Alpha 300 R operating with a green laser at $532 \mathrm{~nm}$. In all the generated spectra, the $\mathrm{D}$ and $\mathrm{G}$ bands were fitted with Lorentzian curves using Origin software and the values of $\mathrm{G}$ and $\mathrm{D}$ band positions and $I_{D} / I_{G}$ ratios were determined graphically by the fitted curves. So the intensities of the bands $\left(\mathrm{I}_{\mathrm{D}}\right.$ and $\left.\mathrm{I}_{\mathrm{G}}\right)$ as well as the $I_{D} / I_{G}$ ratio were determined in this new condition.

In order to evaluate the uncertainties on the $\mathrm{I}_{\mathrm{D}} / \mathrm{I}_{\mathrm{G}}$ values, the standard deviation $(S D)$ of the fluctuations on the base line of each spectrum was determined in the range from 1800 to $2200 \mathrm{~cm}^{-1}$, and the uncertainties (U) for the $I_{D} / I_{G}$ value for every Raman spectrum were calculated using the equation.

$$
U=\frac{I_{D}}{I_{G}} S D \sqrt{\frac{1}{I_{D}^{2}}+\frac{1}{I_{G}^{2}}} .
$$

\section{Results and Discussion}

In the Raman results the $G$ band position was identified and the $\mathrm{I}_{\mathrm{D}} / \mathrm{I}_{\mathrm{G}}$ ratio was calculated to evaluate the crystallinity of the carbon films and its correlation

Table 2. Parameters used in the samples production.

\begin{tabular}{lcccccccc}
\hline Sample Deposition parameters & $\mathrm{Co}-1$ & $\mathrm{Cu}-1$ & $\mathrm{Cu}-2$ & $\mathrm{Cu}-3$ & $\mathrm{Ni}-1$ & $\mathrm{Ni}-2$ & $\mathrm{Ni}-3$ & $\mathrm{Ni}-4$ \\
\hline BL Substrate Temperature $\left({ }^{\circ} \mathrm{C}\right)$ & 600 & 600 & 600 & 500 & 500 & 500 & 500 & 500 \\
C Substrate Temperature $\left({ }^{\circ} \mathrm{C}\right)$ & 18 & 18 & 18 & 18 & 18 & 18 & 18 & 18 \\
BL Sputtering Power (W) & 100 & 30 & 30 & 30 & 75 & 75 & 75 & 75 \\
C Sputtering Power (W) & 150 & 150 & 150 & 150 & 75 & 75 & 75 & 75 \\
BL Deposition Time (min.) & 16 & 32 & 32 & 32 & 120 & 120 & 120 & 120 \\
C Deposition Time (min.) & 60 & 60 & 60 & 60 & 30 & 30 & 60 & 90 \\
BL Working Pressure (mTorr) & 5.0 & 5.0 & 5.0 & 5.0 & 5.0 & 5.0 & 5.0 & 5.0 \\
C Working Pressure (mTorr) & 15.0 & 15.0 & 15.0 & 15.0 & 15.0 & 15.0 & 15.0 & 15.0 \\
BL Gas Flu x (sccm) & 20 & 20 & 20 & 20 & 40 & 40 & 40 & 40 \\
C Gas Flux (sccm) & 40 & 40 & 40 & 40 & 40 & 40 & 40 & 40 \\
Base Pressure (10 & 4.2 & 2.5 & 2.5 & 2.5 & 5.4 & 5.4 & 5.4 & 5.4 \\
\hline
\end{tabular}


with the different parameters used for its production. Low values of $I_{D} / I_{G}$ ratios, for the same $G$ band wavenumber, represent higher crystallinity degrees, being often related to carbon films with lower content of structural defects and also to bigger sized nanographite crystals ${ }^{16}$.

\subsection{Effect of different substrates}

Figure 1 presents the Raman spectra related to samples $\mathrm{Cu}-1$ and $\mathrm{Cu}-2$. According to the amorphization diagram ${ }^{16}$ and considering the small difference in $\mathrm{G}$ band positions, the carbon film of sample $\mathrm{Cu}-2\left(\mathrm{I}_{\mathrm{D}} / \mathrm{I}_{\mathrm{G}}=1.00\right)$ has the highest content of graphite like structure of $\mathrm{sp}^{2}$ microdomains and nanographite crystals, when compared to the carbon film of sample Cu-1 ( $\mathrm{I}_{\mathrm{D}} /$ $\left.\mathrm{I}_{\mathrm{G}}=1.28\right)$. The crystallographic direction of both $\mathrm{Cu}-1$ and $\mathrm{Cu}-2$ buffers was evaluated by $\mathrm{X}$-ray diffraction and both are (111). Therefore, the higher crystallinity of the carbon film on $\mathrm{Cu}-2$ sample corroborates the results found in the literature ${ }^{23,24}$, and is associated to the epitaxial relation between the $\mathrm{Si}$ (111) substrate and the $\mathrm{Cu}$ (111) buffer-layer. In both samples, the films are formed by amorphous carbon, revealed by the presence of the $\mathrm{D}$ band which is more intense for the $\mathrm{Cu}-1$ sample than for the $\mathrm{Cu}-2$. However, the presence and position $\left(1559 \mathrm{~cm}^{-1}\right)$ of the $\mathrm{G}$ band also reveal the existence of nanographite crystals, randomly distributed in the films. All the deposition parameters are similar for both samples $\mathrm{Cu}-1$ and $\mathrm{Cu}-2$, except the type of substrate (see Table 1), showing that the higher crystallinity of $\mathrm{Cu}-2$ sample was due to the use of the $\mathrm{Si}$ (111) substrate.

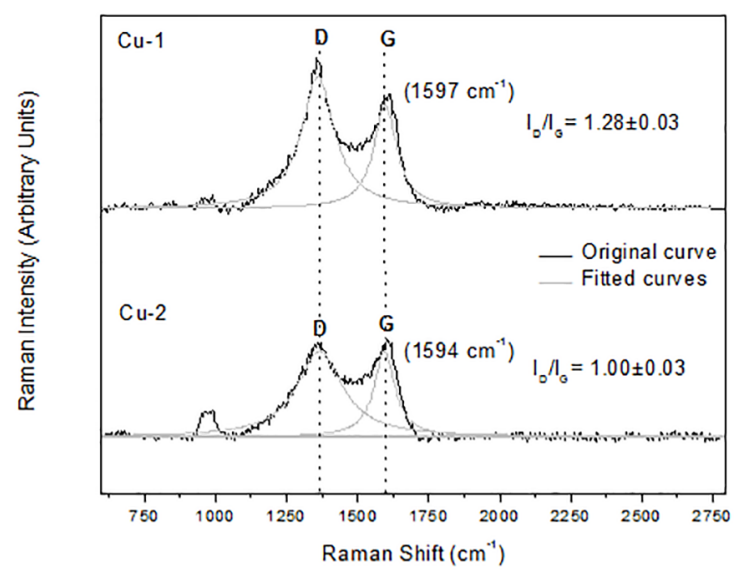

Figure 1. Raman spectra of the samples $\mathrm{Cu}-1$ and $\mathrm{Cu}-2$

\subsection{Effect of different buffer-layers}

In Figures 2, 3 and 4, the Raman spectra of samples Co-1, Ni-3 and $\mathrm{Cu}-3$ are shown, respectively. The redshift in the $G$ bands observed in the spectra and the $I_{D} / I_{G}$ ratios indicate that the amorphization ${ }^{15}$ of the carbon films takes place in the sequence of samples $\mathrm{Cu}-3 \rightarrow \mathrm{Ni}-3 \rightarrow \mathrm{Co}-1$. So amongst the three samples, the carbon film of Co-1 sample presents the highest content of structural defects, and its $\mathrm{G}$ band is the most redshifted when compared to the samples $\mathrm{Ni}-3, \mathrm{Cu}-3$ and also to the one observed in crystalline carbon structures like pristine graphite $\left(1580 \mathrm{~cm}^{-1}\right)^{22-25}$. The peak at $1450 \mathrm{~cm}^{-1}$, observed in the Ni-3 spectrum ( Figure 3 ) was not identified.

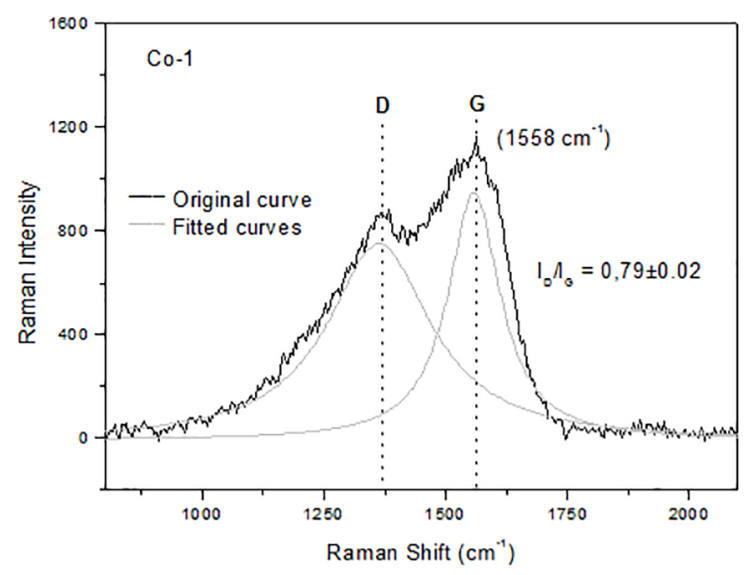

Figure 2. Raman spectrum of Co-1

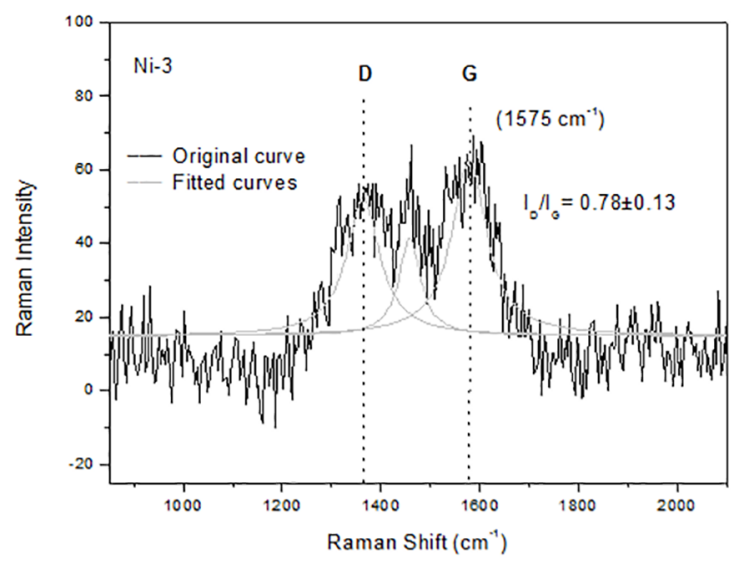

Figure 3. Raman spectrum of $\mathrm{Ni}-3$

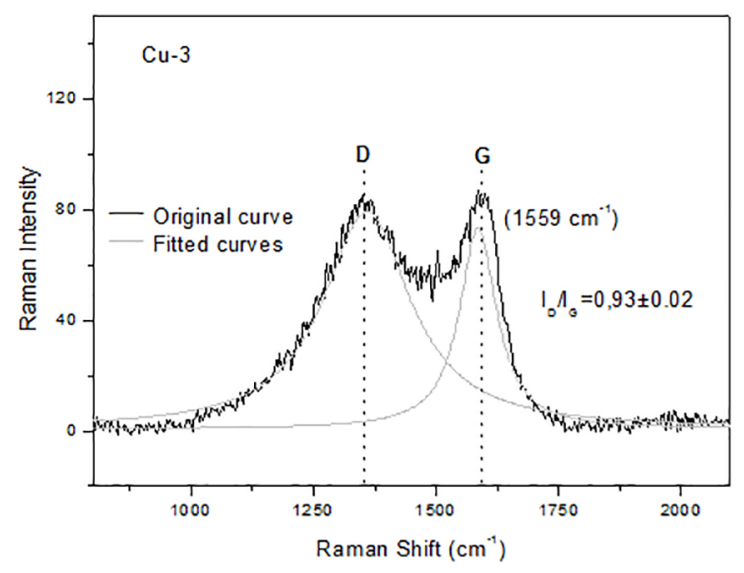

Figure 4. Raman spectrum of $\mathrm{Cu}-3$

The Raman spectra depicted in Figures 2 and 4 is very similar to the spectra of nanographite and activated charcoal, respectively, found in the literature ${ }^{26}$. 


\subsection{Effect of the different heat treatments}

The Raman spectra of samples $\mathrm{Ni}-1$ and $\mathrm{Ni}-2$ are shown in Figures 5 and 6, respectively, where it is possible to compare the results from the different heat treatments employed. In Figure 5, it is observed that the $\mathrm{I}_{\mathrm{D}} / \mathrm{I}_{\mathrm{G}}$ ratio increased, and the $\mathrm{G}$ band position $\left(\mathrm{cm}^{-1}\right)$ was shifted to a higher value after a slow heating rate heat treatment. These facts suggest an enhancement in the disorder of the $\mathrm{sp}^{2}$ structures. In Figure 6 it is observed that the $\mathrm{I}_{\mathrm{D}} / \mathrm{I}_{\mathrm{G}}$ ratio decreased and the $G$ band shifted to a higher value, after a fast heating rate heat treatment. This clearly reveals, supported by Ferrari's diagram ${ }^{15}$, an improvement on the crystallinity of the carbon film in sample $\mathrm{Ni}-2$. This spectrum also shows the presence of a broad band $\left(\sim 1100 \mathrm{~cm}^{-1}\right)$ that might be related to the nanocrystalline phase of diamond, as observed in the literature ${ }^{24}$. Although only sample Ni-1 was heat treated under vacuum conditions, it is observed that the higher heating rate was more efficient to produce a carbon film presenting lower content of structural defects.

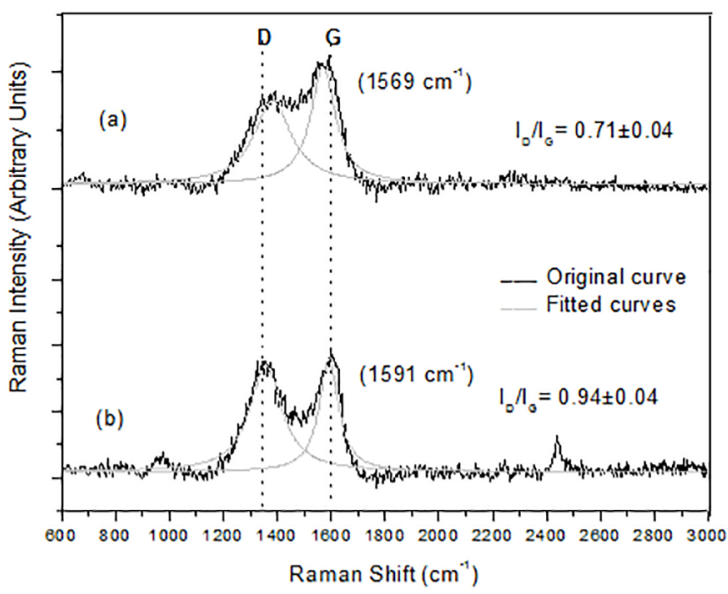

Figure 5. Raman spectra of Ni-1: (a) before the heat treatment and (b) after the heat treatment at slow heating rate

\subsection{Effect of the deposition time}

In function of the very low sputter yield for carbon targets, different times were employed for depositing the carbon films in samples Ni-2, Ni-3 and Ni-4. The Raman spectra for these samples, shown in Figure 7, were evaluated for comparison. The analysis of these spectra shows that the $\mathrm{G}$ band position is the same for all the 3 samples and there is an increase in the $\mathrm{I}_{\mathrm{D}} / \mathrm{I}_{\mathrm{G}}$ ratio as the deposition time of the carbon film is extended from 60 minutes (sample Ni-2) to 90 minutes (sample Ni-4). This increase indicates that longer deposition times are inefficient to obtain carbon films with higher crystallinity.

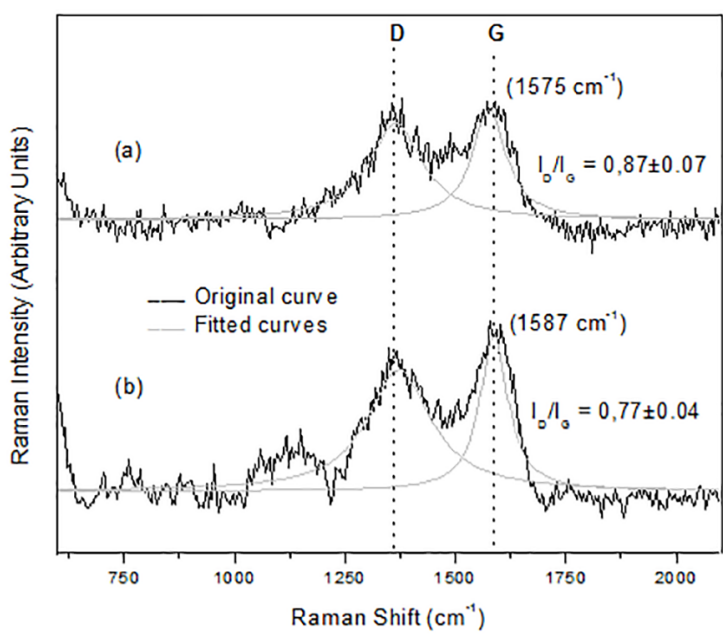

Figure 6. Raman spectra of Ni-2: (a) before the heat treatment and (b) after heating treatment at fast heating rate

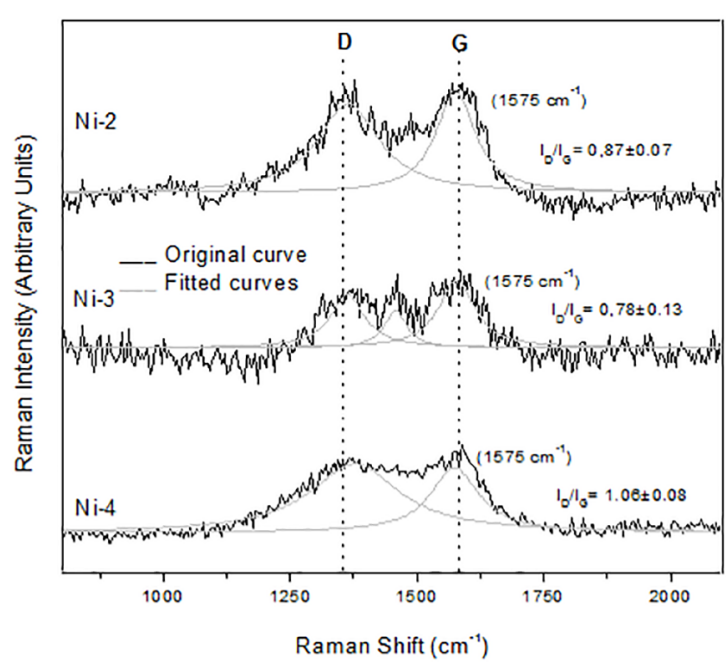

Figure 7. Raman spectra of the samples where the carbon films were deposited: (a) during 30 minutes in sample Ni-2, (b) during 60 minutes in sample Ni-3 and (c) during 90 minutes in sample Ni-4.

\section{Conclusions}

In this work carbon thin films were produced by the magnetron sputtering technique employing different substrates, deposition times, buffer-layers and heat treatments. Raman spectroscopy results were evaluated and they enable to conclude:

- The $\mathrm{I}_{\mathrm{D}} / \mathrm{I}_{\mathrm{G}}$ ratio and $\mathrm{G}$ band position of the carbon films is influenced by the combination between the heat treatments, carbon deposition time, substrates and buffer-layers;

- The carbon film deposited during 60 minutes at $18^{\circ} \mathrm{C}$ on the sapphire substrate with cobalt bufferlayer showed lower crystallinity. 
- $\quad$ Longer deposition times proved to be inefficient to obtain carbon films with better crystallinity.

- High heat treatment rates are adequate for the production of carbon films with higher crystallinities, even without vaccum conditions;

- The adequate epitaxy of carbon on the bufferlayers and substrates influenced positively in the production of carbon films with lower content of structural defects.

The present results showed that the choice of the studied parameters played an important role in the production of carbon thin films deposited by the magnetron sputtering technique and indicate that it can be an alternative method for the production of carbon thin films to be used in advanced scientific researches.

\section{Acknowledgments}

This work was supported by the National Institute of Photonics (INCT de Fotônica) project granted by the Conselho Nacional de Desenvolvimento Científico e Tecnológico - CNPq. The authors are grateful to CNEN for the master's scholarship, to Igor Yamamoto Abe, from the Electrical Engineering Department of the Polytechnic School of the University of São Paulo and Manuel Fernando Gonzalez Huila, from the Chemistry Institute of the University of São Paulo for the Raman measurements.

\section{References}

1. Das RS, Agrawal YK. Raman spectroscopy: Recent advancements, techniques and applications. Vibrational Spectroscopy.2011;57(2):163-176.

2. Schwan J, Ulrich S, Batori V, Ehrhardt H, Silva SRP. Raman spectroscopy on amorphous carbon films. Journal of Applied Physics. 1996;80(1):440-447.

3. Al-Hazmi FS, Beall GW, Al-Ghamdi AA, Alshahrie A, Shokr FS, Mahmoud WE. Raman and ellipsometry spectroscopic analysis of graphene films grown directly on $\mathrm{Si}$ substrate via CVD technique for estimating the graphene atomic planes number. Journal of Molecular Structure. 2016;1118:275-278.

4. Xing Z, Du C, Tian K, Ma F, Shen Y, Zhou J. Application of FTIR-PAS and Raman spectroscopies for the determination of organic matter in farmland soils. Talanta. 2016;158:262-269.

5. Bei K, Zhang C, Wang J, Li K, Lyu J, Zhao J, et al. Solubility and dissolution mechanism of 4-chlorotoluene in subcritical water investigated in a fused silica capillary reactor by in situ Raman spectroscopy. Fluid Phase Equilibria. 2016;425:93-97.

6. Rao KS, Chaudhary AK, Yehya F. Investigation of solid carbon blacks using pulsed photoacoustic and double resonant Raman spectroscopy for the identification of trinitrotoluene. Sensors and Actuators B: Chemical. 2016;231:830-836.

7. Brolly C, Parnell J, Bowden S. Raman spectroscopy: Caution when interpreting organic carbon from oxidizing environments. Planetary and Space Science. 2016;121:53-59.
8. Silva KC, Corio P, Santos JS. Characterization of the chemical interaction between single-walled carbon nanotubes and titanium dioxide nanoparticles by thermogravimetric analyses and resonance Raman spectroscopy. Vibrational Spectroscopy. 2016;86:103-108.

9. Li H, Zhang P, Li G, Lu J, Wu Q, Gu Y. Stress measurement for nonstoichiometric ceria films based on Raman spectroscopy. Journal of Alloys and Compounds. 2016;682:132-137.

10. Robertson J. Diamond-like amorphous carbon. Materials Science and Engineering: R: Reports. 2002;37(4-6):129-281.

11. Chu PK, Li L. Characterization of amorphous and nanocrystalline carbon films. Materials Chemistry and Physics. 2006;96(2-3):253-277.

12. Yurkov AN, Melnik NN, Sychev VV, Savrans VV, Vlasov DV, Konov VI. Synthesis of carbon films by magnetron sputtering of a graphite target using hydrogen as plasmaforming gas. Bulletin of the Lebedev Physics Institute. 2011;38(9):263-266.

13. Safaie P, Eshaghi A, Bakhshi SR. Structure and mechanical properties of oxygen doped diamond-like carbon thin films. Diamond and Related Materials. 2016;70:91-97.

14. Safaie P, Eshaghi A, Bakhshi SR. Optical properties of oxygen dopeddiamond-like carbon thin films. Journal of Alloys and Compounds. 2016;672:426-432.

15. Ferrari AC, Meyer JC, Scardaci V, Casiraghi C, Lazzeri M, Mauri F, et al. Raman Spectrum of Graphene and Graphene Layers. Physical Review Letters. 2006;97(18):187401.

16. Ferrari AC, Robertson J. Raman spectroscopy of amorphous, nanostructured, diamond-like-carbon, and nanodiamond. Philosophical Transactions of the Royal Society A. 2004;362(1824):2477-2512.

17. Silva DLC, Kassab LRP, Martinelli JR, Santos AD, Pillis MF. Production and Characterization of Carbon Thin Films by the Magnetron Sputtering Technique. Materials Science Forum. 2017;881:471-474.

18. Silva DLC, Kassab LRP, Martinelli JR, Santos AD, Ribeiro SJL, Santos MV. Characterization of Thin Carbon Films Produced by the Magnetron Sputtering Technique. Materials Research 2016;19(3):669-672.

19. Ago H, Ito Y, Mizuta N, Yoshida K, Hu B, Orofeo CM, et al. Epitaxial Chemical Vapor Deposition Growth of Single-Layer Graphene over Cobalt Film Crystallized on Sapphire. ACS Nano. 2010;4(12):7407-7414.

20. Orofeo CM, Ago H, Hu B, Tsuji M. Synthesis of large-area, homogeneous, single layer graphene films by annealing amorphous carbon on Co and Ni. Nano Research. 2011;4(6):531-540.

21. McDonough JK, Gogotsi Y. Carbon Onions: Synthesis and Electrochemical Applications. The Electrochemical Society Interface. 2014;22(3):61-66.

22. Yang C, Wu P, Gan W, Habib M, Xu W, Fang Q, et al. Low temperature CVD growth of ultrathin carbon films. AIP Advances. 2016;6(5):055310.

23. Bointon TH, Barnes MD, Russo S, Craciun MF. High Quality Monolayer Graphene Synthesized by Resistive Heating Cold Wall Chemical Vapor Deposition. Advanced Materials. 2015;27(28):4200-4206. 
24. Liu W, Li H, Xu C, Khatami Y, Banerjee K. Synthesis of high-quality monolayer and bilayer graphene on copper using chemical vapor deposition. Carbon. 2011;49(13):4122-4130.

25. Tai FC, Lee SC, Wei CH, Tyan SL. Correlation between I / $\mathrm{I}_{\mathrm{G}}$ Ratio from Visible Raman Spectra and $\mathrm{sp}^{2} / \mathrm{sp}^{3}$ Ratio from
XPS Spectra of Annealed Hydrogenated DLC Film. Materials Transactions. 2006;47(7):1847-1852.

26. Amiri A, Shanbedi M, Ahmadi G, Eshghi H, Kazi SN, Chew BT, et al. Mass production of highly-porous graphene for highperformance supercapacitors. Scientific Reports. 2016;6:32686. 